\title{
Faculty Development in Community Colleges: A Model for Part-Time Faculty
}

\section{Mary Rose Grant}

Saint Louis University

Historically, part-time faculty have not received the same development opportunities as full-time faculty. This study surveyed current practices in faculty development for both full-time and part-time faculty in 232 public two-year colleges throughout the United States. Over $90 \%$ reported that they had a formal faculty development program for both faculty cohorts, funded with 1\%-5\% of their operating budgets. About one half of the colleges designated a faculty development coordinator, used needs assessment to determine program content, and evaluated program outcomes. Results of this study were used to design a generic model for part-time faculty development.

\section{Faculty Development in Community Colleges}

Faculty are the core of any institution of higher education. They are one Thuman resource that is vital to the institution's mission. Community colleges rely on full-time and part-time faculty to meet standards of quality in their teaching mission. The increasing number and reliance on part-time faculty warrants serious consideration in terms of academic quality and institutional integrity (Banachowski, 1996; Gappa \& Leslie, 1993; Roueche, Roueche, \& Milliron, 1995). Faculty development is an institutional commitment to academic integrity (O'Banion, 1994). Faculty development programs serve as vehicles for professional growth and renewal and should be open to all part-time as well as full-time faculty (Murray, 2002; Schuster, 1995). According to national statistics, $64 \%$ of the faculty at community 
colleges was part-time in 1997, an increase of $22 \%$ in five years (American Association of State Colleges and Universities [AASCU], 1999; National Center for Education Statistics, 2002; National Education Association [NEA], 2001). This shift in the demographics of faculty in the community college is not an episodic or short-term trend but a permanent feature in higher education (AASCU, 1999). For community college administrators, assessing the roles and responsibilities of part-time faculty becomes more critical. An investment in support structures for part-time faculty, including integration into the learning community, strengthens the institutional mission (Gappa \& Leslie, 1993, 1997).

This study investigates current practices in faculty development of both full-and part-time faculty in public community colleges of different sizes and accreditation regions. A formal, comprehensive model for part-time faculty development emerges from this study, which identifies elements of planning, implementation, funding, and evaluation.

Historically, before the late 1960s, faculty development programs were essentially nonexistent (Schuster, 1990). Faculty development efforts prior to the mid-1960s were limited to orientation of new faculty, sabbatical leaves, reduced teaching loads, and visiting professorships (Bergquist \& Phillips, 1975).

Faculty development expanded in the 1970s, especially in the area of teaching improvement. The momentum continued to build, providing opportunities to enhance teaching effectiveness, to improve student learning, and to revitalize existing faculty (Gaff, 1975; Hammons, 1983; Richardson \& Moore, 1987).

As the faculty development movement progressed, models were developed that stressed the interrelationship and overlap of all aspects of faculty development: personal, professional, instructional, and organizational (Schuster, 1990). A number of studies in the 1980s recommended the inclusion of part-time faculty in faculty development programs (Miller \& Ratcliff, 1986; Richardson \& Moore, 1987; Williams, 1986).

This study may provide basic information and insights that can be used to initiate, plan, and implement comprehensive faculty development programs in any type of institution of higher education that routinely depends upon the expertise and employment of part-time faculty. The results of this research may also provide demographically different institutions a foundation on which to build formal full-time and part-time faculty development programs and add to the strategies they use to successfully institutionalize these programs. The information garnered from this study was used to inform, plan, 
develop, and implement a comprehensive model of professional development for part-time faculty in Saint Louis University's School for Continuing Education, whose demographics and ratio of full-to part-time faculty is similar to that found in most community colleges.

In addition, a literature search revealed that no studies had compared faculty development programs or practices among accreditation regions. By sampling faculty development programs nationwide, the sub-elements of faculty development programs among accreditation regions were categorized and compared in this study. National data categorized in this way could become a departure point for further investigation into how meeting accreditation performance standards promotes inclusive faculty development as a critical factor in improving teaching and learning.

\section{METHOD}

A random sample of 300 community colleges was selected from an address database provided by the American Association of Community Colleges (AACC) to participate in this nationwide study. A 30-item survey was mailed to the president at each of the colleges to be forwarded to the administrator or faculty member responsible for faculty development. A total of 232 institutions returned completed surveys $(77 \%)$. The survey was divided into six sections to assess program practices, content, coordination, participation, funding, and evaluation associated with faculty development. Responding schools were categorized into six accreditation regions: Middle States Association of Colleges and Schools (MSACS), North Central Association of Colleges and Schools (NCACS), New England Association of Schools and Colleges (NEASC), Northwest Association of Schools and Colleges (NWASC), Southern Association of Colleges and Schools (SACS), and Western Association of Schools and Colleges (WASC). The responding community colleges were also divided into size subcaregories: small, full-time equivalent (FTE) students less than 1,500; medium, FTE students between 1,500 and 4,000; and large, FTE students greater than 4,000. Besides descriptive statistics, chisquare and one-way analysis of variance (ANOVA) were performed to analyze data. 


\section{Results}

\section{Demographics}

Of the 232 responding community colleges, over one-half represented singlecampus institutions $(n=133 ; 57 \%)$ and many were located in rural communities $(n=79 ; 34 \%)$. The response rates by accreditation region were $\operatorname{SACS}(\mathrm{n}=$ $76 ; 83 \%), \operatorname{NCACS}(n=80 ; 82 \%), \operatorname{MSACS}(n=25 ; 78 \%), \operatorname{NWASC}(n=23$; $74 \%)$, WASC ( $n=24 ; 67 \%)$, and NEASC ( $n=4 ; 33 \%)$. The mean FTE number of students at the responding colleges was 3,757, while the ratio of the means of part-time $(n=264)$ to full-time $(n=121)$ faculty was 2 to 1 . Based on the FTE number of students enrolled, more medium sized $(n=92)$ schools were included in the survey than larger $(n=76)$ or smaller schools $(n=64)$.

The mean number of full-time faculty in small colleges was 57; in medium colleges, 95; and in large colleges, 208. A one-way ANOVA of these means was significant, $F(2,229)=38.008, p=.0001$. Small and medium schools had fewer full-time faculty than large schools. The ANOVA for mean number of full-time faculty among accreditation regions was not significant. The mean number of part-time faculty reported by campus and community setting ranged from 197 for single campuses to 355 for multiple campuses and from 120 for schools in rural communities to 421 for schools in urban communities. The ANOVA was significant by college size, $F(2,228)=31.270, p$ $=.0001$, campus setring, $F(1,229)=12.373, p=.001$, and community setting, $F(3,227)=13.160, p=.0001$. Small and medium colleges had fewer part-time faculty than large colleges. Single-campus colleges located in small towns and rural communities had fewer part-time faculty than those with multiple campuses in suburban or urban setrings.

Generally, the person who responded to the survey was an administrator ( $n=206 ; 89 \%)$. Vice presidents for instruction $(n=65 ; 28 \%$ ) or academic deans $(n=55 ; 24 \%)$ most often completed the survey.

Ninety percent $(n=209)$ of colleges reported that they had a formal faculty development program. The mean number of years a formal faculty development program was reported to be in place was 13 . With regard to faculty development program practices, all institutions reported that they provided activities in four areas: professional, personal, curricular, and organizational. Results for the professional subcategory are reported in Table 18.1. 
TABLE 18.1

Number and Percentage of Community Colleges That Provide Professional Development Practices

\begin{tabular}{|c|c|c|c|c|c|c|c|c|c|}
\hline \multirow{3}{*}{ Practice } & \multicolumn{8}{|c|}{ Faculty } & \multirow{3}{*}{$\begin{array}{r}\text { Total } \\
\mathbf{n} \\
\end{array}$} \\
\hline & \multicolumn{2}{|c|}{ Full-Time } & \multicolumn{2}{|c|}{ Part-Time } & \multicolumn{2}{|c|}{ Both } & \multicolumn{2}{|c|}{ Neither } & \\
\hline & $\mathbf{n}$ & $\%$ & $\mathbf{n}$ & $\%$ & $\mathbf{n}$ & $\%$ & $\mathbf{n}$ & $\%$ & \\
\hline Travel funds & 108 & 46.6 & 2 & 0.9 & 122 & 52.6 & 0 & 0.0 & 232 \\
\hline \multicolumn{10}{|l|}{ Released time } \\
\hline On campus & 97 & 42.2 & 1 & 0.4 & 113 & 49.1 & 19 & 8.3 & 230 \\
\hline Off campus & 112 & 48.9 & 1 & 0.4 & 98 & 42.8 & 18 & 7.9 & 229 \\
\hline \multicolumn{10}{|l|}{ Tuition-free courses } \\
\hline On campus & 117 & 50.4 & $\mathbf{0}$ & 0.0 & 73 & 31.5 & 42 & 18.1 & 232 \\
\hline Learning grant & 81 & 35.7 & 0 & 0.0 & 66 & 29.1 & 80 & 35.2 & 227 \\
\hline \multicolumn{10}{|l|}{ Tuition-free courses } \\
\hline Off campus & 90 & 39.3 & $\mathbf{0}$ & 0.0 & 37 & 16.2 & 102 & 44.5 & 229 \\
\hline Return to industry & 94 & 41.0 & $\mathbf{0}$ & 0.0 & 27 & 11.8 & 108 & 47.2 & 229 \\
\hline \multicolumn{10}{|l|}{ Tuition-free courses } \\
\hline Other colleges & 50 & 22.2 & 0 & 0.0 & 16 & 7.1 & 159 & 70.7 & 225 \\
\hline Exchange program & 61 & 27.1 & 0 & 0.0 & 10 & 4.4 & 154 & 68.4 & 225 \\
\hline Sabbatical leave & 168 & 74.3 & 0 & 0.0 & 2 & 0.9 & 56 & 24.8 & 226 \\
\hline Other & 6 & 54.5 & $\mathbf{0}$ & 0.0 & 5 & 45.5 & $\mathbf{0}$ & 0.0 & 11 \\
\hline
\end{tabular}

All responding institutions (100\%) provided travel funds for either fulltime faculty only (47\%) or both full-time and part-time faculty $(53 \%)$, followed by released time for full-time faculty only (49\%) or both faculty cohorts (43\%). Travel funds were more often reported in large schools than medium or small schools for both faculty cohorts. Chi-square was significant, $X^{2}(4, N$ $=232)=12.037, p=.017$, for travel funds. Sabbatical leave $(n=168 ; 74 \%)$ was only offered to full-time faculty. Several significant differences were found among accreditation regions for full-time and part-time faculty for learning grants, $X^{2}(5, N=232)=24.398, p=.0001$, released time on campus, $X^{2}(10$, $N=232)=21.945, p=.015$, released time off campus, $X^{2}(10, N=232)=$ 21.352, $p=.019$, tuition-free courses on campus, $X^{2}(5, N=232)=23.229, p$ 
$=.0001$, and tuition free courses off campus, $X^{2}(5, N=232)=25.358, p=$ .0001 . Professional development practices for both faculty groups were reported more often in the NWASC and WASC accreditation regions than in the other regions, where professional development practices were reported most often for full-time faculty only. The results of personal development practices are presented in Table 18.2.

TABlE 18.2

Number and Percentage of Community Colleges That Provide Personal Development Practices

\begin{tabular}{lrrrrrrrrrr}
\hline \multirow{2}{*}{ Practice } & \multicolumn{1}{c}{ Full-Time } & \multicolumn{1}{c}{ Part-Time } & \multicolumn{2}{c}{ Both } & \multicolumn{2}{c}{ Neither } & Total \\
& n & $\%$ & n & $\%$ & n & $\%$ & n & $\%$ & n \\
\hline Interpersonal skills & 41 & 17.8 & 0 & 0.0 & 100 & 43.5 & 89 & 38.7 & 230 \\
Stress management & 38 & 16.5 & 0 & 0.0 & 99 & 43.0 & 93 & 40.4 & 230 \\
Time management & 36 & 15.7 & 0 & 0.0 & 83 & 36.2 & 110 & 48.0 & 229 \\
Retirement planning & 89 & 38.7 & 0 & 0.0 & 76 & 33.0 & 65 & 28.3 & 230 \\
Other & 3 & 30.0 & 0 & 0.0 & 6 & 60.0 & 1 & 10.0 & 10 \\
\hline
\end{tabular}

Personal development practices were either offered for both full- and parttime faculty $(33 \%-44 \%)$ or not offered at all $(28 \%-48 \%)$. The most often reported personal development practice for full-time faculty only was retirement planning $(n=89 ; 37 \%)$. The three most reported personal development practices for both faculty cohorts were interpersonal skills $(n=100 ; 44 \%)$, stress management $(n=99 ; 43 \%)$, and time management $(n=83 ; 36 \%)$. No significant differences were found for full-time and part-time faculty for personal development practices by college size or accreditation region.

\section{Curricular Development Practices}

Regarding curricular development practices, as represented in Table 18.3, most institutions $(n=162,70 \%)$ reported the availability of curricular practices for both full- and part-time faculties, followed by departmental instructional practices for both $(n=157,68 \%)$. 
TABLE 18.3

Number and Percentage of Community Colleges That Provide Curricular Development Practices

\begin{tabular}{|c|c|c|c|c|c|c|c|c|c|}
\hline \multirow{3}{*}{ Practice } & \multicolumn{8}{|c|}{ Faculty } & \multirow{3}{*}{$\begin{array}{r}\text { Total } \\
\mathrm{n}\end{array}$} \\
\hline & \multicolumn{2}{|c|}{ Full-Time } & \multicolumn{2}{|c|}{ Part-Time } & \multicolumn{2}{|c|}{ Both } & \multicolumn{2}{|c|}{ Neither } & \\
\hline & $\mathbf{n}$ & $\%$ & $\underline{\mathbf{n}}$ & $\%$ & $\mathbf{n}$ & $\%$ & $\mathbf{n}$ & $\%$ & \\
\hline Instructional practices & 36 & 15.7 & 1 & 0.4 & 162 & 70.7 & 30 & 13.1 & 229 \\
\hline Departmental & 35 & 15.2 & 0 & 0.0 & 157 & 68.0 & 39 & 16.9 & 231 \\
\hline Outside consultant & 38 & 16.9 & 0 & 0.0 & 98 & 43.6 & 89 & 39.6 & 225 \\
\hline Teaching networks & 32 & 14.0 & 0 & 0.0 & 46 & 20.1 & 151 & 65.9 & 229 \\
\hline Other & 3 & 42.9 & 0 & 0.0 & 4 & 57.1 & 0 & 0.0 & 7 \\
\hline
\end{tabular}

Two-thirds of the institutions ( $\mathrm{n}=151 ; 66 \%$ ) reported that teaching networks (forums for sharing experiences, instructional tools, and advice among teachers within similar learning environments) were not available to either full- or part-time faculty. No significant differences were reported for full- or part-time faculty for curricular development practices by college size or accreditation region.

\section{Organizational Development Practices}

The results of organizational development are seen in Table 18.4. Orientation of new faculty was reported by most of the responding institutions $(n=182$; $78 \%$ ) for both full and part-time faculty, followed by the provision of faculty handbooks $(n=177 ; 76 \%)$ for both faculty groups. No significant differences were reported for full-time or part-time faculty for organizational development activities by college size or accreditation region.

\section{Faculty Development Program Content}

In the area of faculty development program content, more than one-half ( $\mathrm{n}=$ 133; 58\%) of the reporting institutions used a formal needs assessment to determine program content. The most common assessment method used was a survey $(n=76,61.3 \%)$ done once a year or more $(n=118,91 \%)$. Full-time faculty $(96 \%)$ were more often included in the assessment process than parttime faculty $(69 \%)$. 
TABLE 18.4

Number and Percentage of Community Colleges That Provide Organizational Development Practices

\begin{tabular}{|c|c|c|c|c|c|c|c|c|c|}
\hline \multirow{3}{*}{ Practice } & \multicolumn{8}{|c|}{ Faculty } & \multirow{3}{*}{$\begin{array}{r}\text { Total } \\
\mathbf{n}\end{array}$} \\
\hline & \multicolumn{2}{|c|}{ Full-Time } & \multicolumn{2}{|c|}{ Part-Time } & \multicolumn{2}{|c|}{ Both } & \multicolumn{2}{|c|}{ Neither } & \\
\hline & $\underline{n}$ & $\%$ & $\mathbf{n}$ & $\%$ & n & $\%$ & $\mathbf{n}$ & $\%$ & \\
\hline Orient new faculty & 36 & 15.5 & 3 & 1.3 & 182 & 78.4 & 11 & 4.7 & 232 \\
\hline Faculty handbook & 20 & 8.6 & 10 & 4.3 & 177 & 76.3 & 25 & 10.8 & 232 \\
\hline Policy updates & 37 & 15.9 & 0 & 0.0 & 169 & 72.8 & 26 & 11.2 & 232 \\
\hline Management techniques & $s 34$ & 15.0 & 1 & 0.4 & 60 & 26.4 & 132 & 58.1 & 227 \\
\hline Other & 1 & 50.0 & 0 & 0.0 & 1 & 50.0 & 0 & 0.0 & 2 \\
\hline
\end{tabular}

\section{Faculty Development Coordinator}

A designated faculty development coordinator was reported in one-half (52\%) of responding institutions. Released time (45\%) rather than salary (37\%) was allotted to the faculty development coordinator. Colleges in the WASC region reported that they had a designated faculty development coordinator more often than other regions, $X^{2}(5, N=232)=21.000, p=.001$; however, the WASC colleges provided less compensation in the form of salary than the other regions, $X^{2}(5, N=232)=11.314, p=.045$. Chi-square for faculty development coordination along college size was also significant, $X^{2}(2, N=232)$ $=9.201, p=.01$. The larger schools had more faculty development coordinators, more procedures for selection, and more criteria for qualification than medium or small schools. Responding institutions with no designated faculty development coordinator (48\%) reported that faculty development was the responsibility of the vice president for instruction (53\%) or a faculty development committee (39\%). Chi-square for faculty development coordination by a vice-president for instruction was significant among accreditation regions, $X^{2}(5, N=232)=11.154, p=.048$. The WASC and NEASC regions reported less vice president responsibility for faculty development coordination than other regions.

\section{Faculty Development Program Participation}

With regard to faculty development participation, most responding colleges offered development activities to full-time faculty $(79 \%)$ and part-time faculty $(85 \%)$. Chi-square was significant for full-time faculty participation by 
college size, $X^{2}(2, N=232)=24.073, p=.0001$, and for part-time faculty participation, $X^{2}(2, N=232)=9.532, p=.009$. The larger the college, the more likely it was that either full-time or part-time faculty were eligible to participate. Over one-half the responding colleges (53\%) reported no compensation was available for participation in faculty development activities. The factor most influencing participation was released time $(50 \%)$, followed by personal and professional growth (47\%).

The accreditation regions were divided over compensation for faculty development participation. Most colleges in the NWASC (59\%), SACS (53\%), and WASC $(71 \%)$ provided compensation while most in the MSACS $(76 \%)$, NCACS $(61 \%)$, and NEASC (75\%) did not.

\section{Faculty Development Program Funding}

Nearly all responding colleges $(n=214 ; 93 \%)$ received funding for faculty development programs. The sources for funding most often reported were state funds ( $76 \%$ ), followed by grants ( $43 \%$ ). Some institutions (35\%) reported the use of institutional funds and local operating budgets to support faculty development. The distribution of faculty development program funds was reported to be the responsibility of the vice president for instruction $(50 \%)$ or the faculty development committee (38\%). How funds were distributed was reported to be through the faculty development committee (58\%) and individual departments (36\%), followed by allorments directly to faculty (32\%). The percentage of college budget typically (97\%) allotted to faculty development was under $5 \%$.

Among accreditation regions, there were some significant standouts in the area of funding, $X^{2}(5, N=232)=24.662, p=.0001$. Fewer than half $(48 \%)$ of the colleges in the MSACS reported state funding for faculty development programs. How funds were distribured was significant, $X^{2}(5, N=232)=16.765$, $p=.0005$. MSACS tended $(50 \%)$ to allocate funds directly to faculty more than in other regions. Colleges in WASC rarely allocated funds directly to faculty. Chi-square for funds allocated to part-time faculty was significant, $X^{2}(5$, $N=232)=18.056, p=.003$. In NWASC a larger number of colleges (35\%) target funds specifically for part-time faculty than all other regions $(<11 \%)$.

\section{Faculty Development Program Evaluation}

Less than one-half (47\%) of the community colleges reported that they had a formal evaluation process. Based on college size, chi-square was significant, $X^{2}(2, N=232)=6.507, p=.039$, more medium than large or small schools reported formal evaluation procedures. However, most ( $58 \%$ ) of those who 
reported an evaluation process did not have established criteria for evaluation. Chi-square by accreditation region for program evaluation was significant, $X^{2}(5, N=232)=13.192, p=.022$. The WASC region had formal evaluation procedures more often than other regions. Chi-square for established criteria for program evaluation was also significant, $X^{2}(5, N=232)=14.361$, $p=.013$. The WASC was more likely to provide established criteria than other accreditation regions. Faculty (76\%) and administrators (64\%) were most often reported to participate in the evaluation process. Colleges in the WASC region were less likely to have administrators participate in the evaluation process, $X^{2}(5, N=232)=13.835, p=.017$. The evaluation process was used in most institutions (78\%) to determine new program direction, followed by outcome verification (63\%) in regard to program goals.

\section{Discussion}

Unlike previous research that reported a lack of comprehensive faculty development programs in community colleges (Hoerner, Clowes, \& Impara, 1991; Murray, 1995, 1999, 2002; Richardson \& Moore, 1987), this study concluded that the availability of faculty development in the four subcategories of professional, personal, organizational, and curricular was institution-wide across community colleges and accreditation regions and seemed to be well planned, coordinated, and supported and included part-rime faculty.

Faculty development, as a formalized, structured, and comprehensive program for full- and part-time faculty in United States public community colleges, has grown in depth, breadth, and scope over the past 5 to 10 years. Community colleges are reexamining the role of part-time faculty in their institutions and making efforts to integrate professional, personal, curricular, and organizational goals into their faculty development program practices. The increasing ratio of part-time to full-time faculty (NEA, 2001) may have prompted the increase in practices for faculty development in both cohorts.

Community colleges seem to be more focused on institutional mission, that is, tcaching and learning, than on enhancement of faculty knowledge alone. Hence, the frequency of occurrence of curricular and organizational practices was reported more often than more traditional practices, such as sabbatical leaves and conference attendance. The increase in curricular practices may also indicate that, with changing enrollment patterns, increased requirements for accountability, performance standards, student retention, and learning outcomes, faculty development must include practices to increase faculty knowledge about the teaching and learning process itself. 
Orientation and enculturation of both full-time and part-time faculty is critical to institutional mission. Increased utilization of and reliance on parttime faculty necessitates the increase in efforts to integrate part-time faculty into the mainstream of the campus (Balch, 1999; Banachowski, 1996; Brewster, 2000). This change in faculty demographics changes the way education is delivered. Institutions, in this study, seemed to recognize that organizational fit, job satisfaction, and retention of qualified teaching staff is essential and cost effective.

Many institutions (40\%) reported that personal development practices were not available, and, if they were, the most common was in the area of interpersonal skills. Schuster (1990) predicted an increase in this type of development practice, which could not be documented in this report. In accordance with O'Banion (1994), though, when faculty development for the purpose of personal growth leads to professional growth with improved organizational communication and student interaction and is linked to institutional goals, the result can be better institutions and better education.

With regard to faculty development content, it appears that more institutions are making efforts to meet the needs of individual faculty by developing programs that are cohesive and relevant to faculty interests and demographics and based on assessed needs. This confirmed the findings of Murray (1995, 1999, 2002) and Schuster, Wheeler, and Associates (1990) about faculty ownership of development programs. Also, according to Sandford and McCaslin (2003), community colleges should continually update professional development activities to meet changing faculty needs.

In this study, many vice presidents for instruction or academic deans completed the study survey, suggesting that these positions are most often recognized to be responsible for faculty development, even when a faculty development coordinator was in place. It appears that administrators remain responsible and accountable for implementation of and funding for faculty development programs.

With regard to faculty participation in development activities, it seems that most faculty are eligible. This may be due to several factors: 1) the need for a more technologically oriented and proficient faculty; 2 ) the recognition that a learning institution must promote individual learning for organizational development; and 3) the lifelong learning and continuing education philosophy of the community college dictates inclusion of all. In accord with Balch (1999), as community college leadership recognizes the strategic role all stakeholders play in institutional mission, professional development policies and procedures will be enhanced and better defined. 
Compensation for participation in faculty development is a matter of extrinsic versus intrinsic incentives. Previous researchers reported that community colleges relied on intrinsic rewards based on faculty commitment and individual professionalism as appropriate incentives (Hoerner et al., 1991; Impara, Hoerner, Clowes, \& Allkins, 1991). Sandford and McCaslin (2003) reported that both intrinsic and extrinsic rewards were perceived to be important in influencing part-time faculty participation. From the results of this study, faculty participation was voluntary and more influenced by intrinsic rather than extrinsic incentives or monetary awards.

Most community colleges (93\%) received financial support for faculty development from multiple funding sources and spend $1 \%-5 \%$ of their total budget on faculty development. The cost effectiveness of hiring part-time faculty cannor diminish the need to fund professional development. As the number of part-time faculty increases, hiring rationale must be reexamined. Educational quality rather than economic pressures should weight hiring procedures and influence funding for faculty development.

Confirming the findings by Burnstad (1994), Maxwell and Kazlauskas (1992), and Murray (1999, 2002), most institutions have no formal evaluation process in place or established criteria to evaluate their programs. Evaluation procedures must be planned from the outset and implemented as an integral part of a comprehensive faculty development program in order to be effective.

\section{Conclusions}

Crucial to the academic integrity of the institution and consistent with the teaching and learning mission, community colleges must emphasize the importance of professional development of all faculty. To recruit and retain quality faculty, a formal, comprehensive program to orient, enculturate, renew, and develop all faculty is essential. Faculty development must be an integral part of the institution's strategic plan. Only a systemic approach to faculty development, with high-level administrative support and permanent funding sources, will effect institutional as well as individual change. In creating development programs that are relevant and focused on individual needs, institutions can address the growing diversity of faculty demographics, as well as incorporate processes that promote continuous institutional learning and innovation. Formal program evaluation, with established criteria, is critical to program integrity and viability. Differences in faculty development programs and practices along accreditation regions dictate further investigation of faculty development as tied to assessment, student retention, and learning outcomes. 
Based on these conclusions a formal, systematic, and comprehensive model for faculty development is proposed. The generic nature of the model makes it applicable for either full-or part-time faculty and provides a framework in which the institution can structure an evolutionary faculty development program, which is specific to its culture and faculty demographics.

The components of this model are focused on the organizational, curricular, professional, and personal needs of the faculty and operationalized in five areas: administration, planning, program content, implementation, and evaluation. Administrative support, commitment of time, personnel, and financial resources are vital to program planning and practice. Planning begins with identification of institutional goals and assessment of faculty needs. Given that faculty ownership is imperative to the success of the model, a faculty development coordinator is designated and a council of full-time and part-time faculty selected. This group determines specific competencies, informed by needs analysis, to be achieved by relevant program activities. Measurable objectives are generated and linked to expected outcomes. Program implementation and participation demands program awareness and promotion. Formal criteria for program evaluation are established, which allow for continuous reassessment of program effectiveness.

As community colleges expand efforts to maximize professional development for part-time faculty, a model of development, tailored to achieve identified competencies and linked to institutional mission, can enhance and improve organizational, as well as, individual performance.

\section{REFERENCES}

American Association of State Colleges and Universities. (1999). Facing change: Building the faculty of the future. Washington, DC: Author.

Balch, P. (1999). Part-time faculty are here to stay. Planning for Higher Education, 273), 32-40.

Banachowski, G. (1996). Perspectives and perceptions: The use of part-time faculty in community colleges. Community College Review, 24(2), 49-62.

Bergquist, W. H., \& Phillips, S. R. (1975). Components of an effective faculty development program. Journal of Higher Education, 4Q(2), 177-211.

Brewster, D. (2000). The use of part-time faculty in the community college. Inquiry $5(1), 66-76$. 
Burnstad, H. M. (1994). Management of human resources in the community college. In G. A. Baker, III (Ed.), A handbook on the community college in America: Its history, mission, and management (pp. 386-395). Westport, CT: Greenwood Press.

Eble, K. E., \& McKeachie, W. J. (1985). Improving undergraduate education through faculty development. San Francisco, CA: Jossey-Bass.

Gaff, J. G. (1975). Toward faculty renewal: Advances in faculty, instructional, and organization development. San Francisco, CA: Jossey-Bass.

Gappa, J. M., \& Leslie, D. W. (1993). The invisible faculty: Improving the status of part-timers in higher education. San Francisco, CA: Jossey-Bass.

Gappa, J. M., \& Leslie, D. W. (1997). Two faculties or one? The conundrum of parttimers in a bifurcated workforce (Inquiry No. 6). Washington, DC: American Association for Higher Education.

Hammons, J. (1983). Faculty development: A necessary corollary to faculty evaluation. In A. M. Cohen \& F. B. Brawer (Eds.), New directions for community colleges: No. 41. Evaluating faculty and staff (pp. 75-82). San Francisco, CA: JosseyBass.

Hoerner, J., Clowes, D., \& Impara, J. (1991). Professional development programs in community and technical colleges: Are occupational-technical faculty needs well served? Journal of Srudies in Technical Careers, 13(4), 351-360.

Impara, J., Hoerner, J., Clowes, D., \& Allkins, M. (1991). Professional development programs: A comparison of full-time and part-time occupational faculty. Community Services Catalyst, 2l(2), 8-12.

Maxwell, W. E., \& Kazlauskas, E. J. (1992). Which faculty development methods really work in community colleges? A review of research. Community/Junior College Quarterly, 16, 351-360.

Miller, D. J., \& Ratcliff, J. L. (1986). Analysis of professional activities of lowa Community College faculty. Community/Junior College Journal, 10, 317-343.

Murray, J. P. (1995). Faculty (mis)development in Ohio two-year colleges. Community College Journal of Research and Practice, 19, 549-593.

Murray, J. P. (1999). Faculty development in a national sample of community colleges. Community College Revieus 273), 47-64.

Murray, J. P. (2002). Faculty development in SACS-accredited community colleges. Community College Review, 29(4), 50-67.

National Center for Education Statistics. (2002). A profile of part-time faculty: Fall 1998. Washington, DC: U.S. Department of Education. 
National Education Association Higher Education Research Center. (2001). Parttime faculty. Update, $\pi 4), 1-4$.

O'Banion, T. (1994a). Teaching and learning: A mandate for the nineties. Community College Journal, 64(4), 21-25.

Richardson, R., \& Moore, W. (1987). Faculty development and evaluation in Texas community colleges. Community/Junior College Quarterly, 11, 19-32.

Roueche, J. E., Roueche, S. D., \& Milliron, M. D. (1995). Strangers in their own land: Part-time faculty in American community colleges. Washington, DC: Community College Press.

Sandford, B., \& McCaslin, N. L. ( 2003, October). Assessment of professional development activities, instructional needs, and methods of delivery for part-sime technical and occupational faculty in U.S. community colleges. Paper presented at the Midwest Research to Practice Conference in Adult, Continuing, and Community Education, Columbus, OH. Retrieved May 9, 2004, from http://www.alumni-osu .org/midwest/midwest\%20papers/Sandford\%20\&\%20McCaslin--Done.pdf

Schuster, J. H. (1990). The need for fresh approaches to faculty renewal. In J. H. Schuster, D. W. Wheeler, \& Associates (Eds.), Enhancing faculty careers: Strategies for development and renewal (pp. 3-19). San Francisco, CA: Jossey-Bass.

Schuster, J. H. (1995). Whither the faculty? The changing academic labor market. Educational Record. 76(4), 28-33.

Schuster, J. H., Wheeler, D. W., \& Associares. (Eds.). (1990). Enhancing faculty careers: Strategies for development and renewal. San Francisco, CA: Jossey-Bass.

Williams, J. (1986). A study of professional development practices of part-time instructors at selected League for Innovation community colleges. Los Angeles, CA: League for Innovation in the Community College. 